\title{
Efficient and accurate potential energy surfaces of puckering in sugar-modified nucleosides
}

\author{
Charles-Alexandre Mattelaer,${ }^{\dagger}$ Henri-Philippe Mattelaer,${ }^{\ddagger}$ Jérôme Rihon, ${ }^{\dagger}$ \\ Matheus Froeyen, ${ }^{\dagger}$ and Eveline Lescrinier ${ }^{*} \dagger$ \\ $\dagger K U$ Leuven, Rega Institute for Medical Research, Medicinal Chemistry, Herestraat 49 - \\ Box 1041, 3000 Leuven, Belgium \\ $\ddagger$ Campus Drie Eiken, Laboratory of Medicinal Chemistry, UAntwerp, Universiteitsplein 1, \\ B-2610 Wilrijk, Belgium \\ E-mail: eveline.lescrinier@kuleuven.be
}

\begin{abstract}
Puckering of the sugar-unit in nucleosides and nucleotides is an important structural aspect which directly influences the helical structure of nucleic acids. The preference for specific puckering modes in nucleic acids can be analyzed via in silico conformational analysis but the large amount of conformations and the accuracy of the analysis leads to an extensive amount of computational time. In this paper, we show that the combination of geometry optimizations with the HF-3c method with single point energies at the RI-MP2 level results in accurate results for the puckering potential energy surface (PES) of DNA and RNA nucleosides while reducing the necessary computational time significantly. Applying this method to a series of known xeno nucleic acids (XNAs) allowed us to rapidly explore the puckering PES of each of the respective nucleosides and
\end{abstract}


explore the puckering PES of six-membered modified XNA (HNA and $\beta$-homo-DNA) for the first time.

\section{Introduction}

For nucleic acids, the concept of puckering is used to describe the structural behavior of the sugar moiety which constitutes one of the three fundamental elements of nucleotides. This out-of-plane deviation naturally occurs to reduce electrostatic repulsion and steric strain that a planar conformation induces in a non-aromatic cyclic compound having more than 4 atoms in the ring. The energetic favorable conformers are actively influenced by substituents attached to the cyclic moiety. Puckering of non-aromatic cyclic compounds is typically studied by reducing the dimensionality of the out-of-plane deviation by the concept of pseudorotation. ${ }^{1-3}$ The five-membered ring of (deoxy)ribofuranose in DNA and RNA typically adopts one of two low-energy conformations, namely $\mathrm{C} 3$ '-endo and $\mathrm{C} 2$ '-endo conformation (Figure S1) which directly influences the helical structure of the oligomer. ${ }^{4,5}$ Investigating and understanding the influence of substituents on the puckering behavior in sugar-modified nucleosides is of high importance in drug discovery ${ }^{6}$ and structural biology. ${ }^{7}$ In light of therapeutic strategies, modified nucleic acids have been developed for anticancer strategies, ${ }^{8}$ antiviral compounds, ${ }^{8,9}$ antisense technology ${ }^{10}$ and aptamers. ${ }^{11}$ Modifying the carrier of genetic information in light of xenomicrobiology ${ }^{12}$ has led to the rise of xeno nucleic acids (XNA), where alternative moieties replacing the (deoxy)ribose ring show several benefits

for XNAs over their natural counterparts, including increased thermal stability, increased nuclease resistance and orthogonal hybridization (i.e. disfavoring interactions with natural nucleic acids). With recent advances being made in the rational design of XNA processing enzymes, ${ }^{13}$ the employed models should be able to correctly interpret puckering preferences for these XNA species to correctly interpret and predict protein and substrate interactions. Traditional force fields, used in the analysis of biomolecular structures and interactions, are 
typically parameterized based on quantum mechanic (QM) studies on building blocks of those biomolecules. ${ }^{14-17}$ Although computational studies on single molecules with extensive QM methods have become commonplace, the amount of optimizations required for elaborate conformational analyses do form a bottleneck, specially when computational resources are scarce.

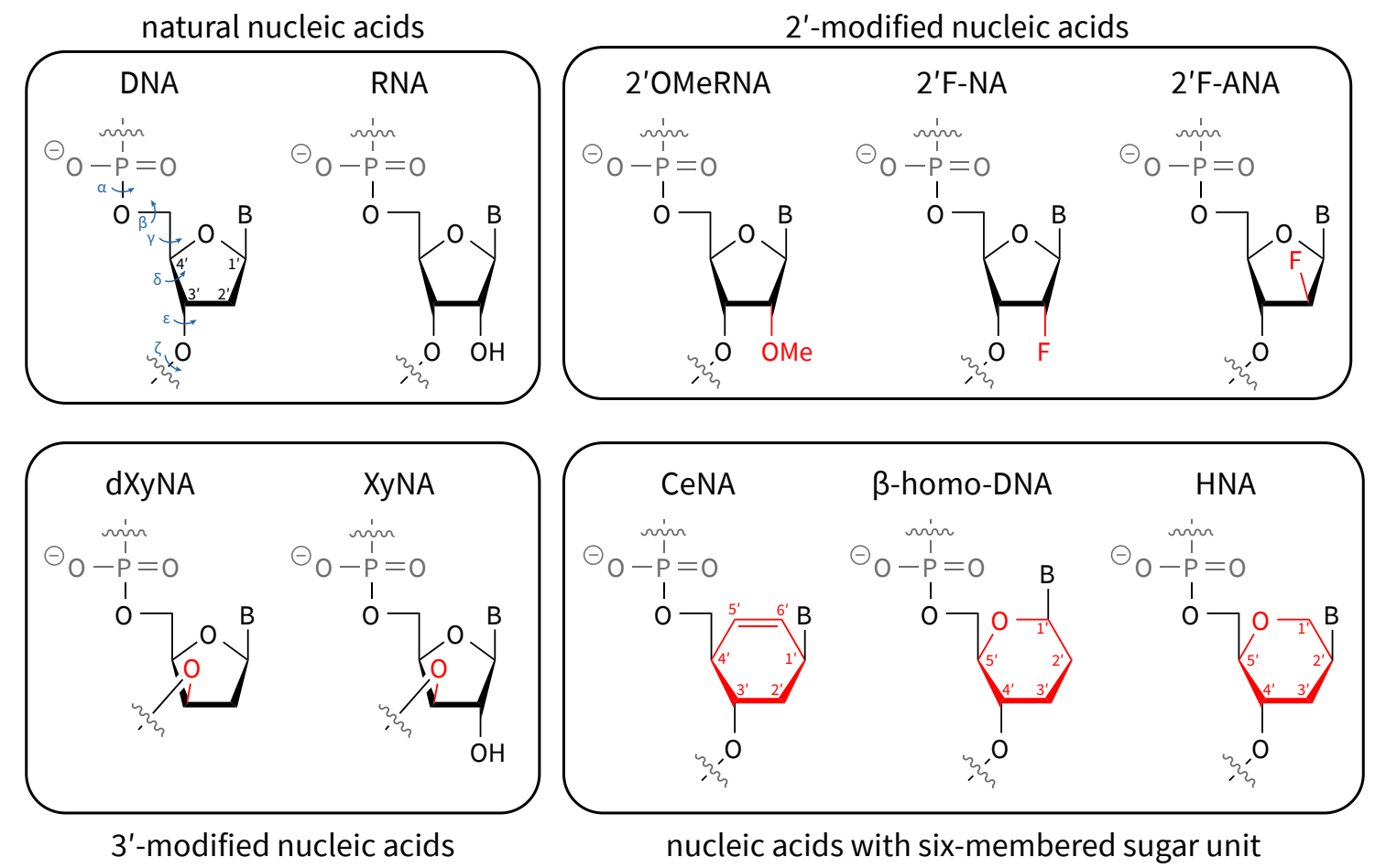

Figure 1: Overview of nucleic acids (grey) subject of this study. All calculations were performed on nucleosides (black). Modifications compared to natural nucleic acids are highlighted in red

Seeking for an in silico tool to perform structural characterization of potential XNA candidatess, we evaluated the use of a lightweight method (HF-3c) ${ }^{18}$ for the geometry optimizations combined with a re-evaluation of the electronic energy of each conformer at the Moller-Plesset second order perturbation (MP2) level of theory for a set of nucleic acids (Figure 1) that ranges from natural DNA and RNA over XNA with minor modifications in the five-membered ribose ring, e.g. 2'-O-methylRNA (2'OMeRNA) and 2'-deoxy-2'fluororibonucleic acid (2'F-RNA), to more significant changes in five-membered ring, e.g. 2'deoxy-2'-fluoroarabinofuranosyl nucleic acid (2'F-ANA), 2'-deoxyxylonucleic acid (dXyNA) 
and xylonucleic acid (XyNA), to XNA with six-membered sugar moieties, i.e. hexitol nucleic acids (HNA) and $\beta-2^{\prime}, 3^{\prime}$-dideoxyglucose nucleic acids (further referred to as homo-DNA). To our knowledge, the only modified, six-membered nucleoside for which a conformational analysis has been previously performed at semi-empirical level (PM3) is the cyclohexene nucleic acid (CeNA). ${ }^{19}$ The unsaturated bond in the sugar moiety allowed for a sampling approach like five-membered rings where the two unsaturated carbons are considered as a single pseudoatom and is therefore termed as a pseudo-five-membered nucleoside. Here, we present an evaluation of the CeNA puckering PES at the HF-3c/RI-MP2 level together with a first conformational analysis of HNA and homo-DNA as true six-membered nucleosides using Pickett angles ${ }^{20,21}$ to sample their conformational globe (Figure S2).

\section{Methods}

\subsection{Sampling of five-membered nucleosides}

For five-membered nucleosides, conformational sampling of the potential energy surface (PES) for ring puckering was performed according to methodology elaborated by Huang et $a .^{22}$ In brief, this method expresses the typical polar coordinates $\left(A_{r}, P_{\theta}\right)^{3}$ in cartesian coordinates $\left(Z_{x}, Z_{y}\right)$ (Figure $\mathrm{S} 1$ ). The cartesian coordinates $Z_{x}$ and $Z_{y}$ are empirically related to two endocylic torsions, $\nu_{1}$ and $\nu_{3}$, by the following expressions:

$$
\begin{aligned}
& Z_{x}=\frac{\nu_{1}+\nu_{3}}{2 \cdot \cos (4 \pi / 5)} \\
& Z_{y}=\frac{\nu_{1}-\nu_{3}}{2 \cdot \sin (4 \pi / 5)}
\end{aligned}
$$

Equations 1 and 2 can simply be rearranged to obtain expressions for $\nu_{1}$ and $\nu_{3}$ in function of $Z_{x}$ and $Z_{y}$. Both $Z_{x}$ and $Z_{y}$ were sampled from $-60^{\circ}$ to $60^{\circ}$ in intervals of $6^{\circ}$ for a total of 441 (21x21) conformations for each five-membered nucleoside (see Figure S3). PES contours were plotted as contour plots using numpy ${ }^{23}$ and matplotlib ${ }^{24}$ after interpolating the data 
at a $1^{\circ}$ interval for both $Z_{x}$ and $Z_{y}$ ordinates.

For each (modified) sugar, nucleosides were considered with adenine, guanine, cytosine and uracyl (or thymine in similarity with DNA if a CH2 group in the sugar moiety is flanking the nucleobase substituent at the $2^{\prime}$ position).

The influence of the $3^{\prime}$ substituent was analyzed for $\mathrm{dxC}$ and $\mathrm{dC}$ with NBO7. ${ }^{25,26}$ Deletion analysis of donor-acceptor interactions between Lewis (filled) and non-Lewis (empty) orbitals was employed to address the effects of the $3^{\prime}$ epimerization on stereoelectronic interactions with the $3^{\prime}-\mathrm{OH}$ substituent.

\subsection{Sampling of six-membered nucleosides}

Pseudorotation in six-membered puckered rings follow the same principle as pseudorotation in five-membered rings. With a well-chosen mean plane, one can quantify the deviation of the atoms with respect to this reference plane. As such, an $N$-membered ring can be represented by an $N-3$ hypersurface. For the particular case of a six-membered ring, this implies that all conformers can be represented on a sphere using the polar coordinates $(Q, \theta, \phi)$ (Figure S2.A). Whereas $Q$ indicates the total puckering amplitude, the distortion of each conformer is indicated by $\theta$ and $\phi .{ }^{3}$ Based on the value of these latter parameters, IUPAC has determined 38 distinct conformers discribing the different geometries attainable by six-membered puckered rings (Figure S2.B). ${ }^{27}$

Since atomic positions are not easily inferred from Cremer-Pople (CP) polar coordinates, the conformational sampling of the puckering PES was accomplished by transforming the polar CP coordinates $(Q, \theta, \phi)$ to a set of Pickett-Strauss (PS) dihedral values (script was available online at http://www.science.unitn.it/ sega/sugars.html) ${ }^{28}$ for HNA and homo-DNA. The CP coordinates were uniformly sampled on the conformational globe for each nucleoside by dividing the surface area of the globe over each point (pseudocode was retrieved from https://www.cmu.edu/biolphys/deserno/pdf/sphere_equi.pdf) for a given $Q$, resulting in 630 conformations per conformational globe. For each of the obtained 
datapoints $(Q, \theta, \phi)$ a respective set of PS angles was then derived and used as optimization restraints to obtain the conformational sampling. The spherical PES plots were generated using the gridfit function available in Matlab (r2020a) instead of the python libraries.

\subsection{Computational details}

To reduce influence of backbone dihedral variation (e.g. intramolecular hydrogen bonding between $5^{\prime}-\mathrm{OH}$ and $\mathrm{O}^{\prime}$ or nucleobase in nucleosides which does not occur in nucleotides), restraints were applied to $\beta, \gamma, \varepsilon$ and $\chi$ dihedrals (Table 1). For XNA with six-membered sugar units (HNA and homo-DNA), backbone torsion angles outside the sugar ring were restrained to reduce steric strain: $\beta$ and $\varepsilon$ were restrained in the antiperiplanar $(a p)$ range whereas $\gamma$ was restrained in + synclinal $(+s c)$ range (Table 1$)$.

Table 1: Backbone restraints used for scanning PES of puckering in specified XNA species. The $2^{\prime}$ torsion indicates $\mathrm{C} 3^{\prime}-\mathrm{C} 2^{\prime}-\mathrm{O} 2^{\prime}-\mathrm{H}\left(\mathrm{O} 2^{\prime}\right)$ in the case of RNA and XyNA or $\mathrm{C} 3^{\prime}-\mathrm{C} 2^{\prime}-$ $\mathrm{O} 2^{\prime}-\mathrm{C}\left(\mathrm{O} 2^{\prime}\right)$ in the case of $2^{\prime} \mathrm{OMeRNA}$.

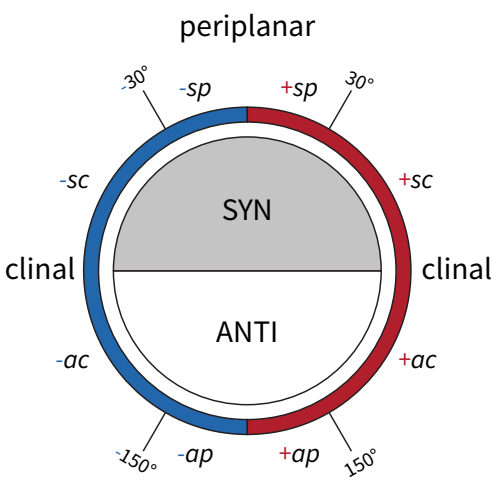

periplanar

\begin{tabular}{|c|c|c|c|c|c|c|c|c|c|c|}
\hline & $\mathrm{DNA}^{a}$ & $\mathrm{RNA}^{a}$ & $2^{\prime} \mathrm{OMeRNA}^{b}$ & $2^{\prime} \mathrm{F}-\mathrm{NA}^{b}$ & $2^{\prime} \mathrm{F}-\mathrm{ANA}^{b}$ & $\mathrm{dXyNA}^{c}$ & $\mathrm{XyNA}^{c}$ & $\mathrm{CeNA}^{d}$ & homo-DNA $^{d}$ & $\mathrm{HNA}^{d}$ \\
\hline$\beta\left(^{\circ}\right)$ & 208.5 & 180.1 & 180.1 & 180.1 & 180.1 & 180.1 & 180.1 & 180.1 & 180.1 & 180.1 \\
\hline$\gamma\left(\left(^{\circ}\right)\right.$ & 30.9 & 47.4 & 47.4 & 47.4 & 47.4 & 240.0 & 240.0 & 60.0 & 60.0 & 60.0 \\
\hline$\varepsilon\left({ }^{\circ}\right)$ & 159.1 & 208.3 & 208.3 & 208.3 & 208.3 & 151.7 & 151.7 & 180.0 & 180.0 & 180.0 \\
\hline$\chi\left({ }^{\circ}\right)$ & 260.6 & 193.9 & 193.9 & 193.9 & 193.9 & 193.9 & 193.9 & - & - & - \\
\hline $2^{\prime}\left(^{\circ}\right)$ & - & 190.3 & 190.3 & - & - & - & 190.3 & - & - & - \\
\hline
\end{tabular}

${ }^{a}$ values were taken from reference ${ }^{22}$ for comparison purposes, ${ }^{b}$ typical A-type helical values were chosen due to their chemical similarity with RNA, ${ }^{c}$ values were chosen based on observed dihedral values in NMR structures $^{29,30},{ }^{d}$ values were chosen to avoid intramolecular interactions while keeping conformational strain to a minimum

Unless otherwise stated, all conformations required for a puckering PES of all included 
nucleic acids in this study were optimized using the HF-3c ${ }^{18}$ method, followed by a single point energy calculation using RI-MP2 ${ }^{31}$ level of theory with the $6-311++\mathrm{G}(2 \mathrm{df}, 2 \mathrm{p})$ basis, further referred to as the "HF-3c/RI-MP2" method. For geometry optimization of local minima at MP2 level, we compared RI-MP2 optimizations for DNA and RNA to assess whether a triple zeta (tz) basis $(6-311++\mathrm{G}(2 \mathrm{df}, 2 \mathrm{p}))$ set is necessary when applying RI approximations to both MP2 density and HF step, i.e. Coulomb and exchange integrals. For all RI-MP2 calculations, the def2-qzvpp/C basis was employed as an auxiliary basis set for the RI approximation of the MP2 density and the def2/JK auxiliary basis set for the RI approximation of Coulomb and exchange integrals in the HF step. All calculations were performed using $\mathrm{ORCA}^{32}$ (v4.2.1). RI-MP2 optimizations of local minima was performed using strict convergence settings (keyword VeryTight0pt).

All discussed computational times are based on our workstation which is equipped with an Intel Xeon E5-2640 v4 (10 cores/20 threads) and 64 GB RAM (2333 MHz). The actual required time will differ for various systems. However, the relative computational cost will remain similar, according to the investigated molecule.

\section{Results and discussion}

\subsection{Benchmark: DNA \& RNA}

Huang and coworkers ${ }^{22}$ provided benchmark PES regarding the puckering of DNA and RNA nucleosides. Their methodology, however, included the geometry optimization of each selected point on the PES at the MP2 level. On our workstations, a geometry optimization at the RI-MP2 level with a double zeta $(\mathrm{dz})$ basis set for these systems using $8 \mathrm{CPU}$ threads required between 45 minutes and 4 hours for our test optimizations depending on starting conformation. Performing all 441 calculations in series would then at least require approximately 13.7 days to fully scan the puckering in a single nucleoside on our system (Figure S4.A). On the other hand, an RI-MP2 optimization using only a single CPU thread 
required approximately 4 hours. In the theoretical case where we could run 16 optimizations independently, this would result in a wall-clock time of approximately 4.6 days to run all optimizations for only a single nucleoside, reducing the calculation runtime by a factor of 3 (Figure S4.B). Running all 441 optimizations at the MP2 level at the same time would be an ideal situation. Unfortunately, this well exceeds the specifications of commonplace workstations since most $a b$ initio methods are very demanding at the hardware level.

The HF-3c method ${ }^{18}$ is a very lightweight method that aims to correct the errors in an HF calculation based on a small basis set using three corrections: geometric counterpoise, dispersion correction and correction for incompleteness of the basis set in short ranges. An optimization using the HF-3c required approximately two to four minutes to complete using only a single CPU thread. Parallelization of the geometry optimizations and resources in mind, a full set of optimizations could be achieved in under three hours if 16 optimizations can run simultaneously which is a significant improvement over optimizing at the (RI-)MP2 level (Figure S4.C). However, running 16 optimizations indepently requires each of these to have a starting conformation. The further the starting conformation from the applied restraints during the optimization, the greater the possibility of the geometry optimization engine falling in the trap of broken geometries. To circumvent this obstacle, we scripted the workflow so each optimization started from a neighboring conformation to reduce the possibility of the geometry optimization engine falling into this trap and lowering the required time for the respective optimization (Figure S4.D). While this does introduce a hierarchy in the order wherein optimizations are to be executed, the relative speed to perform a full puckering PES scan for each nucleoside at HF-3c level well surpasses that of (RI-)MP2, whereafter single point (SP) calculations can be performed. Ultimately, the respective minima are still examined at the RI-MP2 level to give more accurate energy differences.

This approach moved the computational bottleneck from the optimizations to the SP calculations with the extended basis set which typically required 30 minutes or less on a single CPU thread. Since all geometries were available for the SP calculations, we could 
parallelize as much calculations as our CPU allows, keeping in mind some overhead to not oversubscribe the CPU too extensively and creating an additional bottleneck. Parallelizing the SP calculations over $16 \mathrm{CPU}$ threads allowed us to complete all SP calculations in usually less than 12 hours depending on the molecule.

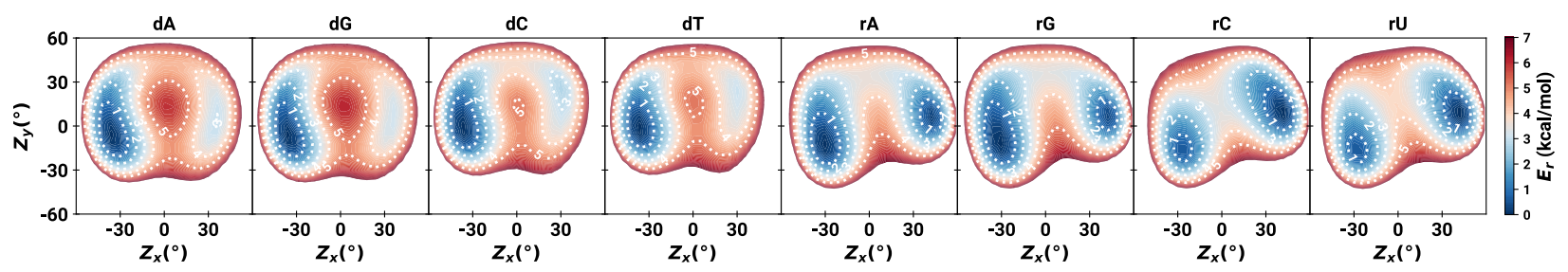

Figure 2: PES of puckering coordinates in DNA (dA, dG, dC, dT) and RNA (rA, rG, rC, rU) nucleosides with the HF-3c/RI-MP2 method. The PES plots for DNA nucleosides show a clear preference for the $\mathrm{C} 2$-endo conformation, whereas the relative energy for the $\mathrm{C} 3{ }^{\prime}$-endo conformation is considerably lower for RNA nucleosides.

The puckering PESs of DNA and RNA nucleosides (Figure 2) obtained by the HF3c/RI-MP2 method are qualitatively nearly identical to the plots obtained at the MP2/6$311++\mathrm{G}(3 \mathrm{df}, 2 \mathrm{p}) / / \mathrm{MP} 2 / 6-31++\mathrm{G}(\mathrm{d}, \mathrm{p})$ level of theory. ${ }^{22}$ Only two observable differences appear in the presented PESs. Firstly, an additional $5 \mathrm{kcal} \mathrm{mol}^{-1}$ contour appears at $(0,15)$ for $\mathrm{dC}$ indicating the relative energy for conformations within this contour to be higher than $5 \mathrm{kcal} \mathrm{mol}^{-1}$. Secondly, the puckering PES for $\mathrm{rU}$ shows a lower transitional barrier depicted by the broader $4 \mathrm{kcal} \mathrm{mol}^{-1}$ contour. As these differences are only minor to the PESs from Huang and coworkers, our HF-3c/RI-MP2 approach can be considered as an efficient yet accurate method to describe the sugar puckering in (deoxy)ribose nucleosides. Additionally, the geometries of optimized minima were compared to evaluate the necessity of the triple zeta basis set (Table 2). Both RI-MP2 with a double and triple zeta basis set deviated several degrees for both $P_{\theta}$ and $A_{r}$. Overall, the geometries obtained with the double zeta basis set were closer to the geometries obtained by Huang and coworkers. The deviation in structural parameters was slightly larger for the geometries obtained with the triple zeta basis set (e.g. $\mathrm{C} 3^{\prime}$-endo of $\mathrm{dA}$ and $\mathrm{dG}$ ) with a maximum $\Delta P_{\theta}$ of $10.3^{\circ}$ and $\Delta A_{r}$ of $4.6^{\circ}$ for $\mathrm{dT}$. The relative energy for DNA nucleosides corresponded well for both basis sets. However, the 
double basis set was less accurate at determining the relative energies between both minima for RNA nucleosides. The offset varied between $0.4 \mathrm{kcal} \mathrm{mol}^{-1}$ to $0.6 \mathrm{kcal} \mathrm{mol}^{-1}$ whereas the maximum offset for relative energy obtained from triple zeta basis set optimizations was $0.2 \mathrm{kcal} \mathrm{mol}^{-1}$ for RNA nucleosides (Table 2). These results indicate that the use of triple zeta basis set is recommended to obtain more accurate relative energies.

Table 2: Comparison of relative energy difference and structural parameters for localized minima at the RI-MP2 level of theory for DNA and RNA nucleosides. Values for geometries optimized using the $6-31++\mathrm{G}(\mathrm{d}, \mathrm{p})$ basis set are indicated with RI-MP2(dz) and for geometries optimized using the $6-311++\mathrm{G}(2 \mathrm{df}, 2 \mathrm{p})$ are indicated with RI-MP2(tz).

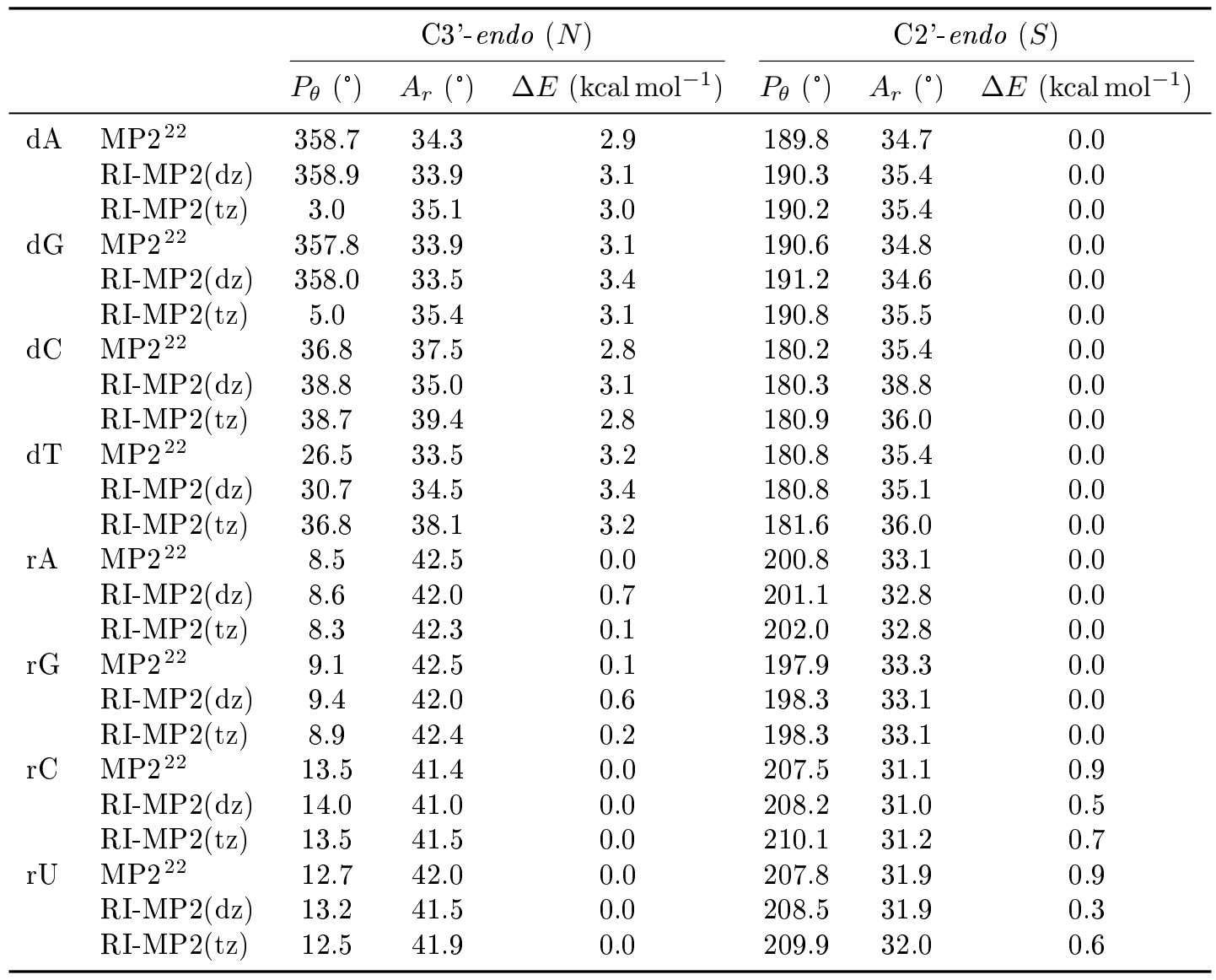




\subsection{Five-membered modified nucleosides}

\subsection{1 $\quad 2^{\prime}$ modified nucleosides: $2^{\prime}$ OMeRNA, $2^{\prime}$ F-NA, $2^{\prime}$ F-ANA}

Modifications at $\mathrm{C} 2$ ' e.g. 2'F-NA and 2'OMeRNA, constitute some of the XNA more closely resembling their natural counterparts as the sugar moiety differs little in chemical structure. In RNA, the 2'-OH substituent acts both as acceptor and donor in a variety of intramolecular hydrogen bonds and plays an important role in enzymatic and non-enzymatic catalysis. The substitution of the reactive hydroxyl group with a chemically more stable methoxy substituent in $2^{\prime}$ OMeRNA results in stable oligonucleotide structures with reduced flexibility. ${ }^{33}$

In experimental structures of $2^{\prime} \mathrm{OMeRNA}$ duplexes, ${ }^{33,34}$ the $\mathrm{C} 3^{\prime}-\mathrm{C} 2^{\prime}-\mathrm{O}^{\prime}-\mathrm{CH}_{3}$ dihedral is typically found in the ap region. The PES plots (Figure 3) of $2^{\prime} \mathrm{OMeRNA}$ were generated at the HF-3c/RI-MP2 level (see Methods). For all four nucleosides, the 2'-methoxy substituent shifts the equilibrium towards $\mathrm{C} 3^{\prime}$-endo conformations in comparison with natural (deoxy)riboses since the relative energy difference between $\mathrm{C} 2$ '-endo and $\mathrm{C} 3{ }^{\prime}$-endo minima is enlarged. This preference in puckering is identical to the puckering of $2^{\prime} \mathrm{OMeRNA}$ residues in crystal structures. ${ }^{33,34}$ In contrast to DNA and RNA, this difference is more pronounced for pyrimidines $\left(2^{\prime} \mathrm{OMeU}=5.5 \mathrm{kcal} \mathrm{mol}^{-1}, 2^{\prime} \mathrm{OMeC}=6.4 \mathrm{kcal} \mathrm{mol}^{-1}\right)$ than for purines $\left(2^{\prime} \mathrm{OMeG}=2.9 \mathrm{kcal} \mathrm{mol}^{-1}, 2^{\prime} \mathrm{OMeA}=3.6 \mathrm{kcal} \mathrm{mol}^{-1}\right)$ for optimized geometries at the RI-MP2(tz) level.

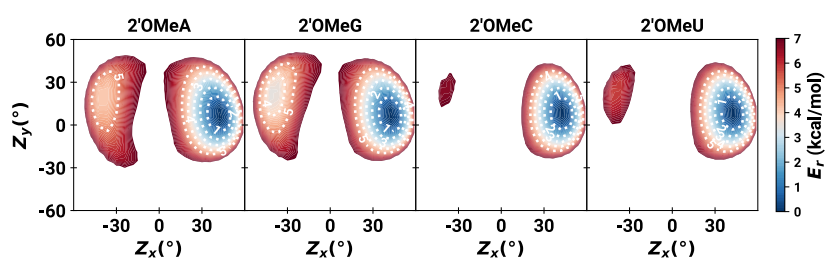

Figure 3: PES of puckering coordinates in 2'OMeRNA nucleosides with the HF-3c/RI-MP2 method.

In $2^{\prime} \mathrm{F}-\mathrm{NA}$, the $2^{\prime}$ hydroxyl is replaced by a single fluorine substituent. The PES plots for $2^{\prime} \mathrm{F}$-NA nucleosides show the same pattern as seen for $2^{\prime} \mathrm{OMeRNA}$, albeit less pronounced, i.e. a shift towards $\mathrm{C} 3{ }^{\prime}-$ endo conformation (Figure 4). Also, a similar trend is observed 
in the difference in relative energy between $\mathrm{C} 3^{\prime}-$ endo and $\mathrm{C} 2^{\prime}-$ endo conformation which ascends from purine to pyrimidine nucleosides: fG $\left(2.8 \mathrm{kcal} \mathrm{mol}^{-1}\right)<\mathrm{fA}\left(3.3 \mathrm{kcal} \mathrm{mol}^{-1}\right)<$ $\mathrm{fU}\left(3.9 \mathrm{kcal} \mathrm{mol}^{-1}\right)<\mathrm{fC}\left(5.5 \mathrm{kcal} \mathrm{mol}^{-1}\right)$. These results agree with experimental crystal structures where all 2'F-NA residues adopt a C $3{ }^{\prime}$-endo conformation. ${ }^{35,36}$ Additionally, these results confirm the general consensus that electronegative $2^{\prime}$-substituents influence the puckering in preference of the $\mathrm{C} 3^{\prime}$-endo conformation. ${ }^{37}$

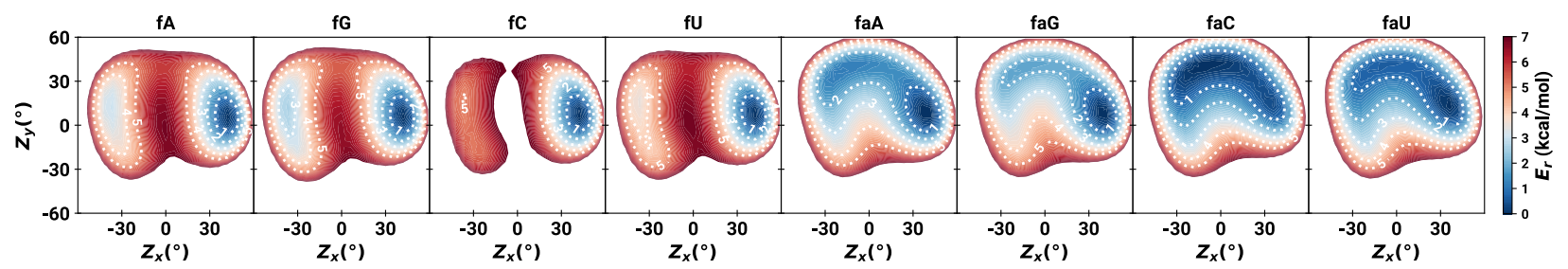

Figure 4: PES of puckering coordinates in $2^{\prime} \mathrm{F}-\mathrm{NA}$ (fA, fG, fC, fU) and $2^{\prime} \mathrm{F}-\mathrm{ANA}$ (faA, faG, $\mathrm{faC}, \mathrm{faU})$ nucleosides with the HF-3c/RI-MP2 method.

Experimental 2'F-ANA structures show a more diverse profile in puckering of the fluoroarabinose sugar moiety compared to five-membered sugars mentioned above. Incorporation of 2'F-ANA thymine residues in B-DNA results in more stable duplexes while retaining the overall B-helical shape. The 2'F-ANA residues were identified to adopt a $\mathrm{O} 4^{\prime}$-endo conformation which was believed to be a result of predominantly steric interactions between $2^{\prime} \mathrm{F}$ and $\mathrm{C} 6$ of the thymine base. ${ }^{38}$ Although the $\chi$ angle was restrained in the ap range (A-type helix) instead of -anticlinal (-ac) range (B-type helix), the PESs of all 2'F-ANA nucleosides show a reduced relative electronic energy for the O4'-endo conformation (Figure 4) instead of the $\mathrm{C} 2$ '-endo conformation. Except for the cytosine analog, all nucleosides favor the C3'-endo conformation over the $\mathrm{O} 4{ }^{\prime}-$ endo conformation at the RI-MP2 level albeit with a small margin $\left(\mathrm{faG}=2.1 \mathrm{kcal} \mathrm{mol}^{-1}, \mathrm{faA}=1.4 \mathrm{kcal} \mathrm{mol}^{-1}, \mathrm{faU}=0.8 \mathrm{kcal} \mathrm{mol}^{-1}, \mathrm{faC}=\right.$ $0.3 \mathrm{kcal} \mathrm{mol}^{-1}$ in favor of $\mathrm{O} 4^{\prime}-$ endo). This preference for the sterically less strained $\mathrm{C} 3^{\prime}$-endo conformation corresponds well with the puckering observed in A-type helices in $2^{\prime} \mathrm{F}-\mathrm{ANA}$ crystals structures. ${ }^{39}$ 


\subsection{2 $\quad 3^{\prime}$ modified nucleosides: $\mathrm{dXyNA}$ and $\mathrm{XyNA}$}

When reviewing literature regarding elucidated (d)XyNA structures, ${ }^{29,30,40-42}$ the major difference with the employed backbone restraints is found in the $\gamma$ dihedral which is mostly found in the $-a c$ range. Therefore, we decided to evaluate the puckering PESs of (d)XyNA nucleosides with the $\gamma$ dihedral restrained in a $-a c$ fashion. The subsequent orientation of O5' did not result in any overlap with $\mathrm{O} 3^{\prime}$ and, hence, the PES showed a shift in favor of C3'-endo conformations (Figure 5), in agreement with the predominant conformation found in NMR solution structures of (d)XyNA. ${ }^{30,41,42}$

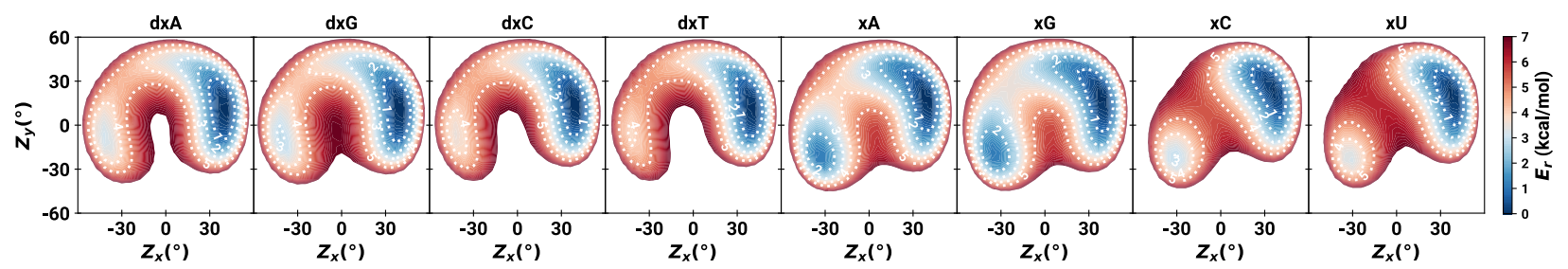

Figure 5: PES of puckering coordinates in dXyNA $(\mathrm{dxA}, \mathrm{dxG}, \mathrm{dxC}, \mathrm{dxT})$ and $\mathrm{XyNA}(\mathrm{xA}$, $\mathrm{xG}, \mathrm{xC}, \mathrm{xU})$ nucleosides with the HF-3c/RI-MP2 method.

The only difference between DNA and dXyNA is the $3^{\prime}$ epimerization. This simple, yet drastic, change completely inverts the conformational preference of the 2 '-deoxy nucleosides in favor of the $\mathrm{C}^{\prime}$-endo conformation. Previous reports already observed this preference in solution NMR, but never rationalized why the epimerization would have such an effect. ${ }^{30,41-45}$ In the current work, deletion analysis of donor-acceptor interactions at the HF level with $\mathrm{NBO} 7$ indicated that interactions with $\mathrm{O}^{\prime}$ for $\mathrm{dC}$ stabilize the $\mathrm{C}^{\prime}$-endo conformation approximately $1 \mathrm{kcal} \mathrm{mol}^{-1}$ more than the $\mathrm{C}^{\prime}$-endo conformation whereas the inverse is observed for $\mathrm{dxC}$ (Table 3). As such, the epimerization shifts the balance by approximately $2 \mathrm{kcal} \mathrm{mol}^{-1}$ in favor of $\mathrm{C} 3^{\prime}$-endo conformation. Notably, interactions with $\mathrm{O} 3^{\prime}-\mathrm{C} 3^{\prime *}$ as acceptor seem to be influenced the most by this epimerization (Table 3). In contrast to natural nucleic acids, the presence of a $2^{\prime}$-hydroxy substituent actually lowers the relative electronic energy of the $\mathrm{C} 2$-endo conformation, instead of favoring the $\mathrm{C} 3$ '-endo conformation. This can be attributed to the diaxal orientation of $2^{\prime}$-hydroxy and $3^{\prime}$-hydroxy substituents in 
the C3'-endo conformation. Such diaxal orientation of vicinal hydroxides is known to be sterically less favorable. ${ }^{46,47}$

Table 3: Donor-acceptor interactions with $\mathrm{O}^{\prime}$ in $\mathrm{dxC}$ and $\mathrm{dC}$ calculated with deletion analysis in NBO7. $E_{\text {del }}$ is reported in $\mathrm{kcal} \mathrm{mol}^{-1}$. A higher $E_{\text {del }}$ indicates a stabilizing effect of the interaction.

\begin{tabular}{lcccccc}
\hline \multirow{2}{*}{ Donor } & \multirow{2}{*}{ Acceptor } & \multicolumn{2}{c}{$\mathrm{dC}$} & & \multicolumn{2}{c}{$\mathrm{dxC}$} \\
\cline { 3 - 4 } \cline { 6 - 7 } & & C2'-endo & C3'-endo & & C2'-endo & C3'-endo \\
\hline O3' (LP1) & C3'-C4'* & 2.3 & 2.7 & & 2.0 & 1.7 \\
O3' (LP1) & C3'-H3'* & 0.3 & 0.3 & & 5.2 & 4.8 \\
O3' (LP1) & C3'-C2'* & 2.9 & 3.5 & & 0.0 & 0.0 \\
O3' (LP2) & C3'-C4'* & 0.8 & 0.9 & & 3.6 & 3.4 \\
O3' (LP2) & C3'-H3'* & 14.9 & 14.1 & & 3.2 & 3.0 \\
O3' (LP2) & C3'-C2'* & 5.1 & 5.1 & & 12.3 & 10.3 \\
C2'-H2' & O3'-C3'* & 4.7 & 0.0 & & 1.3 & 1.6 \\
C2'-H2" & O3'-C3'* & 1.8 & 2.1 & & 0.0 & 5.5 \\
C2'-C1' & O3'-C3'* & 0.0 & 3.5 & & 4.7 & 0.0 \\
C4'-H4' & O3'-C3'* & 2.5 & 1.3 & & 0.0 & 5.2 \\
C4'-C5' & O3'-C3'* & 1.7 & 0.0 & & 0.9 & 1.1 \\
C4'-O4' & O3'-C3'* & 0.0 & 2.3 & & 2.4 & 0.1 \\
\hline Total & & 37.1 & 36.0 & 35.5 & 36.6 \\
\hline
\end{tabular}

\subsection{Pseudo-five-membered nucleosides: CeNA}

Previously reported analysis of the puckering in $\mathrm{CeNA}^{19}$ exploited the rigid endocyclic torsion over the double bond $\left(\nu_{0}\right)$ to consider both unsaturated carbons and the interconnecting double bond as a single pseudoatom. In this approach, the puckering of CeNA was described on a conformational wheel, similar to nucleosides with a five-membered sugar moiety. To re-evaluate the PES of CeNA puckering at the HF-3c/RI-MP2 level, we transformed the $\left(Z_{x}, Z_{y}\right)$ coordinates to the polar puckering parameters $\left(P_{\theta}, A_{r}\right)$ to follow the Fourier transform procedure as previously described. ${ }^{19}$

The evaluation of CeNA puckering at the RI-MP2 level show qualitatively the same preference for C3'-endo conformations (Figure 6) as previously reported at the PM3 level. ${ }^{19}$ However, the energy difference between both conformers $\left(\mathrm{cG}=2.3 \mathrm{kcal} \mathrm{mol}^{-1}, \mathrm{cA}=2.5 \mathrm{kcal} \mathrm{mol}^{-1}\right.$, $\mathrm{cT}=2.0 \mathrm{kcal} \mathrm{mol}^{-1}, \mathrm{cC}=2.5 \mathrm{kcal} \mathrm{mol}^{-1}$ ) is larger than the difference previously reported 
at the PM3 level (approximately $0.5 \mathrm{kcal} \mathrm{mol}^{-1}$ ). ${ }^{19}$ It is important to note that backbone dihedrals for CeNA nucleosides have been restrained in this study for the consistency of the methodology and to prevent influence of backbone dihedrals. As the previous PM3 study did not restrain backbone dihedrals and did not report on conformational changes in backbone dihedrals, it is difficult to compare the results. However, it is unlikely that the dihedrals remained constant over the PES without restraints, possibly reducing the energy difference between the $\mathrm{C} 3^{\prime}$-endo and $\mathrm{C} 2$ '-endo conformation due to favorable reorientation of backbone dihedrals in different nucleoside conformations. In either case, the $\mathrm{C} 3{ }^{\prime}-$ endo remains the preferred conformation on the puckering PES of CeNA. The unrestrained $\chi$ dihedral remained in the high anti region for all optimized CeNA geometries at the RI-MP2(tz) level of theory (Table S1).

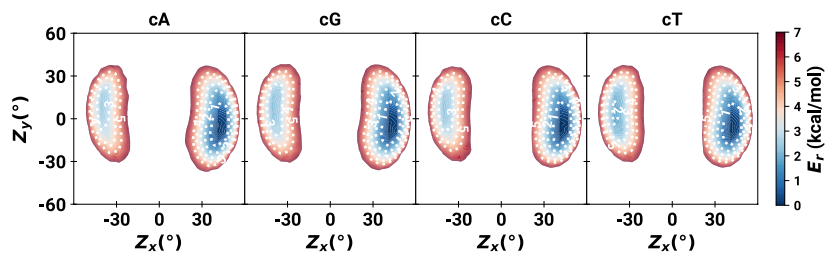

Figure 6: PES of puckering coordinates in CeNA nucleosides with the HF-3c/RI-MP2 method.

\subsection{Six-membered modified nucleosides: HNA \& homo-DNA}

HNA and homo-DNA are both XNA with six-membered sugar moieties that have been examined from a therapeutic and xenobiological perspective. Experimental duplex structures for both XNA have been described at the atomic resolution, ${ }^{48-51}$ but no single stranded structure with different secondary motifs, e.g. loops, have been experimentally elucidated to date. Although both XNA show a structural preference for a particular chair conformation of the six-membered sugar moiety, a duplex structure for homo-DNA has been identified where a single residue adopted a boat conformation. ${ }^{48,51}$

Obtained conformational globes of $\mathrm{hA}$ and $\mathrm{ddA}$ are quite similar when compared from different angles (Figure 7). However, rather low transition energies between different ddA 

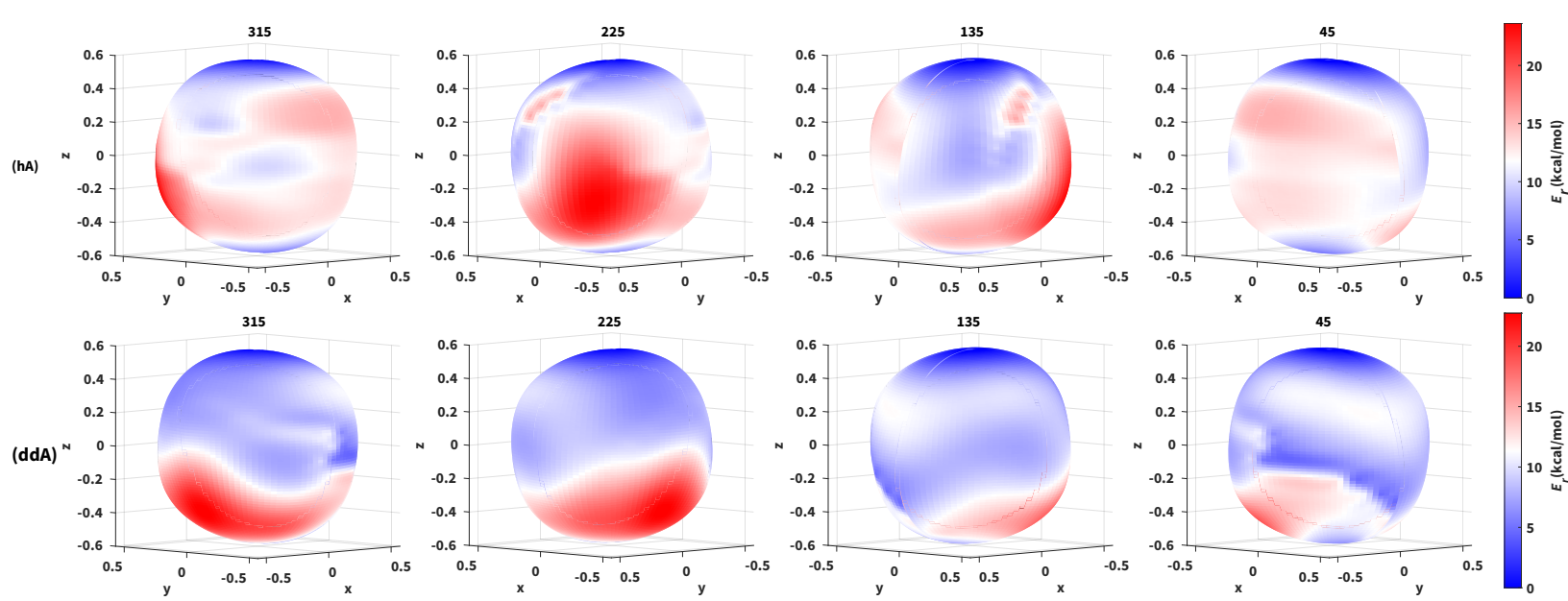

Figure 7: Comparison of corresponding views on the conformational globe of hA (HNA) and ddA (homo-DNA). Erratic changes in $E_{r}$ are due to unrestrained changes in $\chi$ angle.

conformations are visible in contrast to hA. From the analyzed low energy conformers of homo-DNA (Table 4), the ${ }^{1^{\prime}} S_{5^{\prime}}$ and ${ }^{O^{\prime}} S_{2^{\prime}}$ conformations are conformations with similar relative energy as compared to five-membered nucleosides (approximately $3 \mathrm{kcal} \mathrm{mol}^{-1}$ ). The boat conformation identified by Egli and coworkers ${ }^{48}$ seems of ${ }^{\prime}, 3^{\prime} B$ type which is closely related to the ${ }^{O^{\prime}} S_{2^{\prime}}$ conformation. Although the relative energy of the ${ }^{1^{\prime}} C_{4^{\prime}}$ conformation for homo-DNA purines remains below $5 \mathrm{kcal} \mathrm{mol}^{-1}$, the relative energy of these conformations for the pyrimidine counterparts well exceeds $5 \mathrm{kcal} \mathrm{mol}^{-1}$. The necessary change in $\chi$ to the $-s c$ range causes a short distance between $\mathrm{O} 2$ of pyrimidine nucleobases and $\mathrm{H} 3^{\prime}$ which probably introduces strain on the molecule. For HNA (Table 5), the search for low energy conformers seems even more difficult. Except for hG, the ${ }^{3 \prime} S_{1^{\prime}}$ conformations returned the lowest relative energy compared to the respective ${ }^{4^{\prime}} C_{1^{\prime}}$ conformation $\left(\mathrm{hA}=3.9 \mathrm{kcal} \mathrm{mol}^{-1}\right.$, $\left.\mathrm{hT}=2.8 \mathrm{kcal} \mathrm{mol}^{-1}, \mathrm{hC}=3.5 \mathrm{kcal} \mathrm{mol}^{-1} \mathrm{~mol}\right)$. The relatively low energy of the ${ }^{3^{\prime}} S_{1^{\prime}}$ conformations are possibly attributed to favorable electrostatic interactions between $\mathrm{O} 3^{\prime}$ and $\mathrm{H} 8^{\prime} / \mathrm{H} 6^{\prime}$ atoms. The position of the nucleobase on $\mathrm{C} 2^{\prime}$ requires a less drastic change in $\chi$ angle for the ${ }^{4^{\prime}} C_{1^{\prime}}$ conformation, resulting in a relatively low energy of this conformation especially for purines $\left(\mathrm{hA}=4.6 \mathrm{kcal} \mathrm{mol}^{-1}, \mathrm{hG}=3.7 \mathrm{kcal} \mathrm{mol}^{-1}, \mathrm{hC}=5.5 \mathrm{kcal} \mathrm{mol}^{-1}, \mathrm{hT}=\right.$ $4.5 \mathrm{kcal} \mathrm{mol}^{-1}$ ). The complete set of conformational globes for homo-DNA (Figure S5) and 
HNA (Figure S6) are available in the supplementary information.

Table 4: Low energy conformers for homo-DNA nucleosides.

\begin{tabular}{|c|c|c|c|c|c|c|}
\hline & Conformation & $\theta\left({ }^{\circ}\right)$ & $\phi\left({ }^{\circ}\right)$ & $Q\left(^{\circ}\right)$ & $\chi\left(\left(^{\circ}\right)\right.$ & $E_{r}\left(\mathrm{kcal} \mathrm{mol}^{-1}\right)$ \\
\hline \multirow[t]{6}{*}{$\mathrm{ddA}$} & $4^{\prime} C_{1^{\prime}}$ & 1.2 & 92.8 & 32.9 & 201.5 & 0.0 \\
\hline & ${ }^{1^{\prime}} C_{4^{\prime}}$ & 167.2 & 340.3 & 28.5 & 312.5 & 4.5 \\
\hline & $1^{\prime}, 4^{\prime} B$ & 85.4 & 220.6 & 38.8 & 296.2 & 6.2 \\
\hline & $1^{\prime}, 4^{\prime} B$ & 85.3 & 71.6 & 38.4 & 221.0 & 5.9 \\
\hline & ${ }^{\prime} S_{5^{\prime}}$ & 91.4 & 278.3 & 41.2 & 178.9 & 2.5 \\
\hline & $O^{\prime} S_{2^{\prime}}$ & 93.8 & 326.8 & 43.7 & 193.7 & 3.2 \\
\hline \multirow[t]{6}{*}{$\mathrm{ddG}$} & $4^{\prime} C_{1^{\prime}}$ & 1.4 & 88.4 & 32.9 & 206.4 & 0.0 \\
\hline & ${ }^{1^{\prime}} C_{4^{\prime}}$ & 167.5 & 343.9 & 28.3 & 310.2 & 3.6 \\
\hline & $1^{\prime}, 4^{\prime} B$ & 86.2 & 224.3 & 38.5 & 296.5 & 5.5 \\
\hline & $1^{\prime}, 4^{\prime} B$ & 85.2 & 71.5 & 38.3 & 232.2 & 5.6 \\
\hline & $1^{\prime} S_{5^{\prime}}$ & 92.2 & 281.9 & 40.9 & 184.2 & 2.9 \\
\hline & $O^{\prime} S_{2^{\prime}}$ & 93.86 & 327.8 & 43.8 & 195.8 & 3.2 \\
\hline \multirow[t]{6}{*}{$\mathrm{ddC}$} & $4^{\prime} C_{1^{\prime}}$ & 1.5 & 72.9 & 33.0 & 203.1 & 0.0 \\
\hline & ${ }^{1^{\prime}} C_{4^{\prime}}$ & 168.8 & 336.3 & 28.3 & 128.2 & 8.3 \\
\hline & ${ }^{1^{\prime}, 4^{\prime}} B$ & 89.6 & 230.4 & 38.3 & 294.6 & 9.9 \\
\hline & $1^{\prime}, 4^{\prime} B$ & 84.8 & 70.3 & 38.4 & 206.4 & 6.8 \\
\hline & ${ }^{1^{\prime}} S_{5^{\prime}}$ & 92.5 & 285.6 & 40.5 & 193.1 & 3.7 \\
\hline & $O^{\prime} S_{2^{\prime}}$ & 93.2 & 327.8 & 43.7 & 198.2 & 3.7 \\
\hline \multirow[t]{6}{*}{$\mathrm{ddT}$} & $4^{\prime} C_{1^{\prime}}$ & 1.3 & 91.8 & 32.9 & 211.8 & 0.0 \\
\hline & ${ }^{1^{\prime}} C_{4^{\prime}}$ & 169.4 & 339.9 & 28.3 & 127.7 & 6.0 \\
\hline & $1^{\prime}, 4^{\prime} B$ & 89.5 & 231.2 & 38.1 & 295.8 & 7.7 \\
\hline & $1^{\prime}, 4^{\prime} B$ & 86.2 & 72.3 & 38.0 & 226.3 & 6.0 \\
\hline & ${ }^{1}{ }^{\prime} S_{5^{\prime}}$ & 93.0 & 287.1 & 40.3 & 194.2 & 3.8 \\
\hline & $O^{\prime} S_{2^{\prime}}$ & 94.0 & 326.1 & 43.1 & 200.1 & 3.8 \\
\hline
\end{tabular}

Especially for HNA where the energy minima seem to be isolated by higher transition states on the conformational globe, overall flexibility of the XNA could be significantly hampered. To fold in a stable tertiary structure, an XNA oligonucleotide should be able to form loops which are one of the simplest secondary structural elements in oligonucleotides. ${ }^{52,53}$ The formation of such loops typically requires the extension of the P-P distance between nucleotides, usually arising from an increased flexibility in sugar moieties or a change in sugar conformation of loop residues compared to the helical residues. ${ }^{4,52}$ As mentioned before, such an alternating puckering motif has only been experimentally observed for homo-DNA and not HNA. 
Table 5: Low energy conformers for HNA nucleosides.

\begin{tabular}{|c|c|c|c|c|c|c|}
\hline & Conformation & $\theta\left(^{\circ}\right)$ & $\phi\left(^{\circ}\right)$ & $Q\left(^{\circ}\right)$ & $\chi\left(\left(^{\circ}\right)\right.$ & $E_{r}\left(\mathrm{kcal} \mathrm{mol}^{-1}\right)$ \\
\hline \multirow[t]{5}{*}{ hA } & ${ }^{4} C_{1^{\prime}}$ & 0.8 & 38.5 & 31.9 & 210.6 & 0.0 \\
\hline & ${ }^{1^{\prime}} C_{4^{\prime}}$ & 173.1 & 292.2 & 30.6 & 245.2 & 4.6 \\
\hline & $1^{\prime}, 4^{\prime} B$ & 91.5 & 222.9 & 44.0 & 71.9 & 5.4 \\
\hline & ${ }^{1^{\prime}} S_{3^{\prime}}$ & 86.8 & 200.8 & 42.8 & 215.7 & 6.0 \\
\hline & ${ }^{3} S_{1^{\prime}}$ & 87.4 & 29.9 & 43.3 & 243.5 & 3.9 \\
\hline \multirow[t]{5}{*}{ hG } & $4^{\prime} C_{1^{\prime}}$ & 0.6 & 0.1 & 31.9 & 210.5 & 0.0 \\
\hline & ${ }^{1} C_{4^{\prime}}$ & 172.7 & 290.4 & 30.7 & 249.0 & 3.7 \\
\hline & $1^{\prime}, 4^{\prime} B$ & 91.7 & 222.3 & 43.7 & 64.5 & 4.8 \\
\hline & ${ }^{1^{\prime}} S_{3^{\prime}}$ & 87.2 & 202.2 & 43.1 & 216.4 & 5.4 \\
\hline & ${ }^{3} S_{1^{\prime}}$ & 87.9 & 28.2 & 43.5 & 240.8 & 5.4 \\
\hline \multirow[t]{5}{*}{$\mathrm{hC}$} & $4^{\prime} C_{1^{\prime}}$ & 2.6 & 245.5 & 31.5 & 204.4 & 0.0 \\
\hline & ${ }^{1^{\prime}} C_{4^{\prime}}$ & 175.2 & 290.2 & 30.2 & 241.8 & 5.5 \\
\hline & $1^{\prime}, 4^{\prime} B$ & 90.8 & 219.3 & 43.0 & 269.6 & 7.8 \\
\hline & ${ }^{1^{\prime}} S_{3^{\prime}}$ & 86.3 & 199.5 & 42.2 & 213.2 & 7.3 \\
\hline & $3^{\prime} S_{1^{\prime}}$ & 88.8 & 25.2 & 43.6 & 220.3 & 3.5 \\
\hline \multirow[t]{5}{*}{ hT } & $4^{\prime} C_{1^{\prime}}$ & 2.5 & 233.3 & 31.3 & 207.5 & 0.0 \\
\hline & ${ }^{1^{\prime}} C_{4^{\prime}}$ & 175.8 & 289.3 & 30.2 & 243.3 & 4.5 \\
\hline & $1^{\prime}, 4^{\prime} B$ & 91.5 & 219.6 & 42.7 & 253.0 & 7.0 \\
\hline & ${ }^{1^{\prime}} S_{5^{\prime}}$ & 87.4 & 200.3 & 41.8 & 219.8 & 6.8 \\
\hline & $O^{\prime} S_{2^{\prime}}$ & 88.8 & 26.0 & 43.4 & 228.4 & 2.8 \\
\hline
\end{tabular}

\section{Conclusion}

A combined approach of the lightweight HF-3c method with the well-known (RI-)MP2 method was evaluated for the efficient and accurate calculation of the PES of puckering in natural nucleic acids and several XNA. Although the method cannot attain the accuracy of MP2 geometries and electronic energies (without RI approximations), the error is almost negligible and as such the method can be employed for general conformational sampling approaches when computational resources are limited or access to high-performance computing is unavailable.

The puckering PES of selected five-membered XNA species and CeNA showed great resemblance with available data on these XNAs. The effect of electronegative $2^{\prime}$-substituents was confirmed by exploring the PES of $2^{\prime} \mathrm{OMeRNA}$ and $2^{\prime} \mathrm{F}-\mathrm{NA}$. A first attempt at describing the influence of the $3^{\prime}$ epimerization in (d)XyNA on the stereoelectronics was performed, indicating that predominantly donor-acceptor type interactions with $\mathrm{O} 3^{\prime}-\mathrm{C} 3^{\prime *}$ are influenced 
by this epimerization. Although the relative energy for the $\mathrm{C} 2{ }^{\prime}$-endo conformation seems enlarged at the MP2 level, the re-evaluation of CeNA at the MP2 level did not drastically alter the previous perspective.

Folded structures of single stranded XNA with six-membered "sugars" in the backbone are not experimentally determined so far. The formation of a stable tertiary structures requires secondary structural elements (e.g. loops) that contain a variation in puckering modes in available structures of folded nucleic acids with five-membered sugars. The relatively high electronic energy of conformers, other than the most stable ${ }^{4^{\prime}} C_{1^{\prime}}$, observed here for HNA and homo-DNA could indicate that such required flexibility might be hampered and dependent on external influences.

The efficient method presented in this work to determine the complete puckering PES of potential new XNA candidates can provide interesting structural information at the start of projects. Calculating the PES of the "sugar" in XNA can be a helpful tool in the selection of most suitable XNA candidates in applications for which stable folding is required, e.g. aptamer development. Moreover, it can complement and facilitate the experimental structure determination of novel XNA structures.

\section{Acknowledgement}

Charles-Alexandre Mattelaer is an $\mathrm{SB} \mathrm{PhD}$ fellow at the Research Foundation - Flanders (FWO) (1S23217N). The authors would like to thank Chantal Biernaux for editorial assistance.

\section{Supporting Information Available}

Graphical illustrations of the pseudorotation in both five- and six-membered rings are presented in the supporting information. Additionally, illustrations of the sampling approach and HNA/homo-DNA PES plots are available in the supporting information. This informa- 
tion is available free of charge via the Internet at http://pubs.acs.org .

\section{References}

(1) Kilpatrick, J. E.; Pitzer, K. S.; Spitzer, R. The Thermodynamics and Molecular Structure of Cyclopentane. J. Am. Chem. Soc. 1947, 69, 2483-2488.

(2) Altona, C.; Sundaralingam, M. Conformational analysis of the sugar ring in nucleosides and nucleotides. New description using the concept of pseudorotation. J. Am. Chem. Soc. 1972, 94, 8205-8212.

(3) Cremer, D.; Pople, J. A. A General Definition of Ring Puckering Coordinates. J. Am. Chem. Soc. 1975, 97, 1354-1358.

(4) Saenger, W. Principles of Nucleic Acid Structure; 1984; pp 1-8.

(5) Vargason, J. M.; Henderson, K.; Ho, P. S. A crystallographic map of the transition from B-DNA to A-DNA. Proc. Natl. Acad. Sci. U.S.A. 2001, 98, 7265-7270.

(6) Yamamoto, T.; Nakatani, M.; Narukawa, K.; Obika, S. Antisense drug discovery and development. Future Med. Chem. 2011, 3, 339-365.

(7) Anosova, I.; Kowal, E. A.; Dunn, M. R.; Chaput, J. C.; Horn, W. D.; Egli, M. The structural diversity of artificial genetic polymers. Nucleic Acids Res. 2016, 44, 10071021.

(8) Jordheim, L. P.; Durantel, D.; Zoulim, F.; Dumontet, C. Advances in the development of nucleoside and nucleotide analogues for cancer and viral diseases. Nat. Rev. Drug. Discov. 2013, 12, 447-464.

(9) Yates, M. K.; Seley-Radtke, K. L. The evolution of antiviral nucleoside analogues: A review for chemists and non-chemists. Part II: Complex modifications to the nucleoside scaffold. Antiviral Res. 2019, 162, 5-21. 
(10) Khvorova, A.; Watts, J. K. The chemical evolution of oligonucleotide therapies of clinical utility. Nat. Biotechnol. 2017, 35, 238-248.

(11) Keefe, A. D.; Pai, S.; Ellington, A. Aptamers as therapeutics. Nat. Rev. Drug. Discov. 2010, 9, 537-550.

(12) Pinheiro, V. B.; Taylor, A. I.; Cozens, C.; Abramov, M.; Renders, M.; Zhang, S.; Chaput, J. C.; Wengel, J.; Peak-Chew, S.-Y.; McLaughlin, S. H.; Herdewijn, P.; Holliger, P. Synthetic Genetic Polymers Capable of Heredity and Evolution. Science 2012, $336,341-344$.

(13) Vanmeert, M.; Razzokov, J.; Mirza, M. U.; Weeks, S. D.; Schepers, G.; Bogaerts, A.; Rozenski, J.; Froeyen, M.; Herdewijn, P.; Pinheiro, V. B.; Lescrinier, E. Rational design of an XNA ligase through docking of unbound nucleic acids to toroidal proteins. Nucleic Acids Res. 2019, 47, 7130-7142.

(14) Zgarbová, M.; Otyepka, M.; Šponer, J.; Mládek, A.; Banáš, P.; Cheatham, T. E.; Jurečka, P. Refinement of the Cornell et al. Nucleic Acids Force Field Based on Reference Quantum Chemical Calculations of Glycosidic Torsion Profiles. J. Chem. Theory Comput. 2011, 7, 2886-2902.

(15) Zgarbová, M.; Luque, F. J.; Šponer, J.; Cheatham Iii, T. E.; Otyepka, M.; Jurečka, P. Toward Improved Description of DNA Backbone: Revisiting Epsilon and Zeta Torsion Force Field Parameters. J. Chem. Theory Comput. 2013, 14, 2339-2354.

(16) Zgarbová, M.; Šponer, J.; Otyepka, M.; Cheatham, T. E.; Galindo-Murillo, R.; Jurečka, P. Refinement of the Sugar-Phosphate Backbone Torsion Beta for AMBER Force Fields Improves the Description of Z- and B-DNA. J. Chem. Theory Comput. 2015, $11,5723-5736$.

(17) Wang, L. P.; McKiernan, K. A.; Gomes, J.; Beauchamp, K. A.; Head-Gordon, T.; Rice, J. E.; Swope, W. C.; Martínez, T. J.; Pande, V. S. Building a More Predictive 
Protein Force Field: A Systematic and Reproducible Route to AMBER-FB15. J. Phys. Chem. B 2017, 121, 4023-4039.

(18) Sure, R.; Grimme, S. Corrected small basis set Hartree-Fock method for large systems. J. Comput. Chem. 2013, 34, 1672-1685.

(19) Nauwelaerts, K.; Lescrinier, E.; Sclep, G.; Herdewijn, P. Cyclohexenyl nucleic acids: Conformationally flexible oligonucleotides. Nucleic Acids Res. 2005, 33, 2452-2463.

(20) Pickett, H. M.; Strauss, H. L. Conformational Structure, Energy, and Inversion Rates of Cyclohexane and Some Related Oxanes. J. Am. Chem. Soc. 1970, 92, 7281-7290.

(21) Pickett, H. M.; Strauss, H. L. Symmetry and Conformation of the Cycloalkanes. J. Chem. Phys. 1971, 55, 324-334.

(22) Huang, M.; Giese, T. J.; Lee, T. S.; York, D. M. Improvement of DNA and RNA sugar pucker profiles from semiempirical quantum methods. J. Chem. Theory Comput. 2014, $10,1538-1545$.

(23) Harris, C. R.; Millman, K. J.; van der Walt, S. J.; Gommers, R.; Virtanen, P.; Cournapeau, D.; Wieser, E.; Taylor, J.; Berg, S.; Smith, N. J.; Kern, R.; Picus, M.; Hoyer, S.; van Kerkwijk, M. H.; Brett, M.; Haldane, A.; del Río, J. F.; Wiebe, M.; Peterson, P.; Gérard-Marchant, P.; Sheppard, K.; Reddy, T.; Weckesser, W.; Abbasi, H.; Gohlke, C.; Oliphant, T. E. Array programming with NumPy. Nature 2020, 585, 357-362.

(24) Hunter, J. D. Matplotlib: A 2D Graphics Environment. Comput. Sci. Eng. 2007, 9, $90-95$.

(25) Glendening, E. D.; Landis, C. R.; Weinhold, F. NBO 7.0: New vistas in localized and delocalized chemical bonding theory. J. Comput. Chem. 2019, 40, 2234-2241.

(26) Patrascu, M. B.; Malek-Adamian, E.; Damha, M. J.; Moitessier, N. Accurately modeling 
the conformational preferences of nucleosides. J. Am. Chem. Soc. 2017, 139, 1362013623.

(27) IUPAC-IUB Joint Commission on Biochemical Nomenclature (JCBN), Conformational Nomenclature for Five and Six-Membered Ring Forms of Monosaccharides and Their Derivatives. Recommendations 1980. Eur. J. Biochem. 1980, 111, 295-298.

(28) Sega, M.; Autieri, E.; Pederiva, F. Pickett angles and Cremer-Pople coordinates as collective variables for the enhanced sampling of six-membered ring conformations. Mol. Phys. 2011, 109, 141-148.

(29) Ramaswamy, A.; Smyrnova, D.; Froeyen, M.; Maiti, M.; Herdewijn, P.; Ceulemans, A. Molecular Dynamics of Double Stranded Xylo-Nucleic Acid. J. Chem. Theory Comput. 2017, 13, 5028-5038.

(30) Mattelaer, C.; Maiti, M.; Smets, L.; Maiti, M.; Schepers, G.; Mattelaer, H.-P.; Rosemeyer, H.; Herdewijn, P.; Lescrinier, E. Stable Hairpin Structures Formed by XyloseBased Nucleic Acids. ChemBioChem 2021, cbic.202000803.

(31) Feyereisen, M.; Fitzgerald, G.; Komornicki, A. Use of approximate integrals in ab initio theory. An application in MP2 energy calculations. Chem. Phys. Lett. 1993, 208, 359363.

(32) Neese, F. The ORCA program system. WIREs Comput. Mol. Sci. 2012, 2, 73-78.

(33) Lubini, P.; Zürcher, W.; Egli, M. Stabilizing effects of the RNA 2'-substituent: crystal structure of an oligodeoxynucleotide duplex containing 2'-O-methylated adenosines. Chem. Biol. 1994, 1, 39-45.

(34) Adamiak, D. A.; Milecki, J.; Popenda, M.; Adamiak, R. W.; Dauter, Z.; Rypniewski, W. R. Crystal structure of 2'-O-Me(CGCGCG)2, an RNA duplex at 1.30 
A resolution. Hydration pattern of 2'-O-methylated RNA. Nucleic Acids Res. 1997, 25, 4599-4607.

(35) Manoharan, M.; Akinc, A.; Pandey, R. K.; Qin, J.; Hadwiger, P.; John, M.; Mills, K.; Charisse, K.; Maier, M. A.; Nechev, L.; Greene, E. M.; Pallan, P. S.; Rozners, E.; Rajeev, K. G.; Egli, M. Unique Gene-Silencing and Structural Properties of 2'FluoroModified siRNAs. Angew. Chem., Int. Ed. 2011, 50, 2284-2288.

(36) Pallan, P. S.; Greene, E. M.; Jicman, P. A.; Pandey, R. K.; Manoharan, M.; Rozners, E.; Egli, M. Unexpected origins of the enhanced pairing affinity of 2'-fluoro-modified RNA. Nucleic Acids Res. 2011, 39, 3482-3495.

(37) Deleavey, G. F.; Damha, M. J. Designing chemically modified oligonucleotides for targeted gene silencing. Chem. Biol. 2012, 19, 937-954.

(38) Berger, I.; Tereshko, V.; Ikeda, H.; Marquez, V. E.; Egli, M. Crystal structures of B-DNA with incorporated implications of conformational preorganization for duplex stability. Nucleic Acids Res. 1998, 26, 2473-2480.

(39) Li, F.; Sarkhel, S.; Wilds, C. J.; Wawrzak, Z.; Prakash, T. P.; Manoharan, M.; Egli, M. 2'-Fluoroarabino- and Arabinonucleic Acid Show Different Conformations, Resulting in Deviating RNA Affinities and Processing of Their Heteroduplexes with RNA by RNase $\mathrm{H} \dagger$, ‡. Biochemistry 2006, 45, 4141-4152.

(40) Ramaswamy, A.; Froeyen, M.; Herdewijn, P.; Ceulemans, A. Helical structure of xyloseDNA. J. Am. Chem. Soc. 2010, 132, 587-595.

(41) Maiti, M.; Siegmund, V.; Abramov, M.; Lescrinier, E.; Rosemeyer, H.; Froeyen, M.; Ramaswamy, A.; Ceulemans, A.; Marx, A.; Herdewijn, P. Solution structure and conformational dynamics of deoxyxylonucleic acids (dXNA): An orthogonal nucleic acid candidate. Chem. - Eur. J. 2012, 18, 869-879. 
(42) Maiti, M.; Maiti, M.; Knies, C.; Dumbre, S.; Lescrinier, E.; Rosemeyer, H.; Ceulemans, A.; Herdewijn, P. Xylonucleic acid: Synthesis, structure, and orthogonal pairing properties. Nucleic Acids Res. 2015, 43, 7189-7200.

(43) Rosemeyer, H.; Seela, F. 1-(2'-Deoxy- $\beta$-D-xylofuranosyl)thymine Building Blocks for Solid-Phase Synthesis and Properties of Oligo(2'-Deoxyxylonucleotides). Helv. Chim. Acta 1991, 74, 748-760.

(44) Rosemeyer, H.; Krecmerova, M.; Seela, F. 9-(2'-Deoxy- $\beta$-D-xylofuranosyl)adenine Building Blocks for Solid-Phase Synthesis and Properties of Oligo(2'-deoxyxylonucleotides). Helv. Chim. Acta 1991, 74, 2054-2067.

(45) Rosemeyer, H.; Strodtholz, I.; Seela, F. 2'-Deoxy- $\beta$-D-xylothymidinyl- $\left(3^{\prime}, 5^{\prime}\right)-2^{\prime}$-deoxy$\beta$-D-xylothymidylate: stereochemical course of dinucleoside phosphonate formation and conformational properties. Bioorg. Med. Chem. Lett. 1992, 2, 1201-1206.

(46) Abraham, R. J.; Koniotou, R.; Sancassan, F. Conformational analysis. Part 39. A theoretical and lanthanide induced shift (LIS) investigation of the conformations of cyclopentanol and cis- and trans-cyclopentane-1,2-diol. J. Chem. Soc., Perkin Trans. 2 2002, 2025-2030.

(47) Chen, X.; Walthall, D. A.; Brauman, J. I. Acidities in cyclohexanediols enhanced by intramolecular hydrogen bonds. J. Am. Chem. Soc. 2004, 126, 12614-12620.

(48) Egli, M.; Pallan, P. S.; Pattanayek, R.; Wilds, C. J.; Lubini, P.; Minasov, G.; Dobler, M.; Leumann, C. J.; Eschenmoser, A. Crystal structure of homo-DNA and nature's choice of pentose over hexose in the genetic system. J. Am. Chem. Soc. 2006, 128, 10847-10856.

(49) Lescrinier, E.; Esnouf, R.; Schraml, J.; Busson, R.; Heus, H.; Hilbers, C.; Herdewijn, P. Solution structure of a HNA-RNA hybrid. Chem. Biol. 2000, 7, 719-731. 
(50) Lescrinier, E.; Esnouf, R. M.; Schraml, J.; Busson, R.; Herdewijn, P. Solution Structure of a Hexitol Nucleic Acid Duplex with Four Consecutive T.T Base Pairs. Helv. Chim. Acta 2000, 83, 1291-1310.

(51) Sheehan, J. H.; Smith, J. A.; Pallan, P. S.; Lybrand, T. P.; Egli, M. Molecular dynamics simulation of homo-DNA: The role of crystal packing in duplex conformation. Crystals 2019, 9, 1-14.

(52) Varani, G. Exceptionally stable nucleic acid hairpins. Annu. Rev. Biophys. Biomol. Struct. 1995, 24, 379-404.

(53) Zacharias, M. Conformational analysis of DNA-trinucleotide-hairpin-loop structures using a continuum solvent model. Biophys. J. 2001, 80, 2350-2363. 


\section{Graphical TOC Entry}

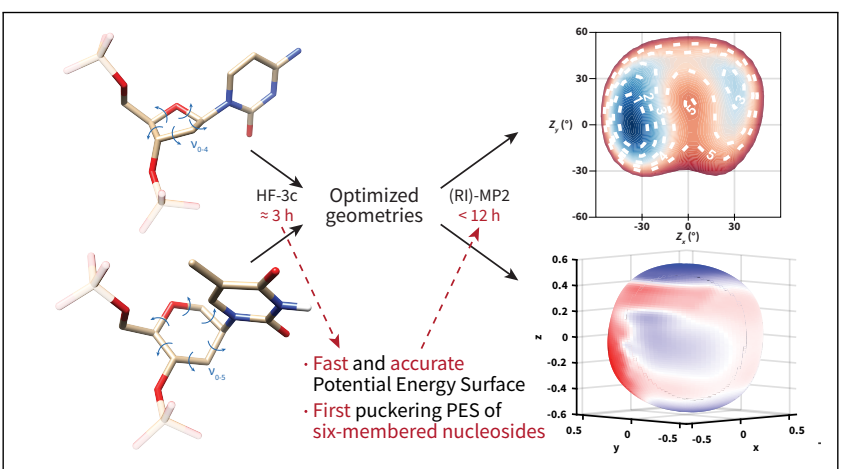

